\title{
Using GIS for Time Series Analysis of the Dead Sea from Remotely Sensing Data
}

\author{
Maher A. El-Hallaq1, Mohammed O. Habboub² \\ ${ }^{1}$ Surveying and Geodesy, Civil Engineering Department, The Islamic University of Gaza, Gaza, Palestine \\ ${ }^{2}$ GIS, IT Department, The University College of Applied Science, Gaza, Palestine \\ Email: mhallaq@iugaza.edu.ps, mhabboub@ucas.edu.ps
}

Received 22 September 2014; revised 20 October 2014; accepted 15 November 2014

Copyright @ 2014 by authors and Scientific Research Publishing Inc.

This work is licensed under the Creative Commons Attribution International License (CC BY).

http://creativecommons.org/licenses/by/4.0/

(c) () OP

\section{Abstract}

Developed tools of Remote Sensing and Geographic Information System are rapidly spread in recent years in order to manage natural resources and to monitor environmental changes. This research aims to study the spatial behavior of the Dead Sea through time. To achieve this aim, time series analysis has been performed to track this behavior. For this purpose, fifteen satellite imageries are collected from 1972 to 2013 in addition to 2011-ASTGTM-DEM. Then, the satellite imageries are radiometrically and atmospherically corrected. Geographic Information system and Remote Sensing techniques are used for the spatio-temporal analysis in order to detect changes in the Dead Sea area, shape, water level, and volume. The study shows that the Dead Sea shrinks by $2.9 \mathrm{~km}^{2} /$ year while the water level decreases by $0.65 \mathrm{~m} /$ year. Consequently, the volume changes by $-0.42 \mathbf{~ k m}^{3} /$ year. The study has also concluded that the direction of this shrinkage is from the north, northwest and from the south direction of the northern part due to the nature of the bathymetric slopes. In contrast, no shrinkage is detected from the east direction due to the same reason since the bathymetric slope is so sharp. The use of the Dead Sea water for industrial purposes by both Israel and Jordan is one of the essential factors that affect the area of the Dead Sea. The intensive human water consumption from the Jordan and Yarmouk Rivers for other usages is another main reason of this shrinkage in the area as well.

\section{Keywords}

Dead Sea, Time Series Analysis, Remote Sensing, GIS

\section{Introduction}

Understanding changes in wetlands, land-uses, seashores and vegetation areas over time is essential to many as- 
pects of engineering, geographic and planning researches. Interpretation and analysis of remotely sensed imagery require an understanding of the processes that determine the relationships between the property the sensor actually measures and the surface properties we are interested in identifying and studying [1].

Changes of the earth's surface are becoming more and more important in monitoring the local, regional and global resources. Large collection of past and present remote sensing imagery makes it possible to analyze the spatio-temporal pattern of environmental elements and impact of human activities in past decades [2]. Reference [3] defines change detection as the process of identifying differences in the state of an object or phenomenon by observing it at different time. Another definition of change detection is a technology ascertaining the changes of specific features within a certain time interval. It provides the spatial distribution of features, qualitative and quantitative information of features changes [4]. Simply, US Department of Defense defines change detection as an image enhancement technique that compares two images of the same area from different time periods. Identical picture elements are eliminated, leaving signatures that have undergone change.

Change detection algorithms analyze multiple images of the same scene- taken at different times—to identify regions of change [5]. Reference [3] classifies change detection methods into two types, namely, classification comparison and direct comparison. Reference [6] proposes a classification of three categories, including pixelbased, feature-based and object-based change detection. Reference [7] generalizes the change detection methods into seven types, namely, arithmetic operation, transformation, classification comparison, advanced models, GIS integration, visual analysis and some other methods. Reference [8] summarizes change detection methods in general terms and proposes a classification of direct difference, statistical hypothesis testing, predictive models, shading model, and background modeling and so on.

Reference [2] classifies change detection from its approaches, namely, bi-temporal change detection and temporal trajectory analysis. The former measures changes based on a "two-epoch" timescale, i.e. the comparison between two dates. The latter analysis the changes based on a "continuous" timescale, i.e. the focus of the analysis is not only on what has changed between dates, but also on the progress of the change over the period. Reference [5] classifies change detection algorithms as algorithms based on pixel amplitude, both the magnitude and phase, or on transformed pixel values. Reference [9] classifies change detection methods based on history since the algebra techniques such as image differencing or image rationing were the first techniques used to characterize changes in digital imagery then more complex techniques were developed since then with the improvement of processing capacities but also with the development of new theoretical approaches.

\section{Research Problem}

According to [10], the decrease of inflow into the Dead Sea is causing its shoreline to undergo very fast and to change dynamically in its area. The area of the Dead Sea surface —at the end of the 1950's—was about 1000 $\mathrm{km}^{2}$ of which about $757 \mathrm{~km}^{2}$ where located in the northern part and $240 \mathrm{~km}^{2}$ in the southern part. Other studies state that the water level of the Dead Sea is dropping by an average of $0.9 \mathrm{~m}$ per year [11], while [12] illustrates that the Dead Sea has been experiencing a severe drop in level since 1978 with an average of $0.7 \mathrm{~m} /$ year.

\section{The Study Area}

The Dead Sea is located on $31^{\circ} 30^{\prime} \mathrm{N}, 35^{\circ} 30^{\prime} \mathrm{E}$, WGS84 reference datum, bordering Jordan to the east, historical Palestine and the West Bank to the west. The Dead Sea is considered as the lowest point on the Earth's surface at about $-400 \mathrm{~m}$ [13]. The east and west shores of the Dead Sea are bounded by towering fault escarpments that form part of the African-Syrian rift system. The valley slopes gently upward to the north along the Jordan River, and to the south along the Wadi Araba. Since 1978, the Dead Sea has retreated, and the sea body turned into two basins: The principal northern one that is about $308 \mathrm{~m}$ deep (in 1997), and the shallow southern one with the Lisan (or Lashon) Peninsula and the Lynch Straits in between, which has a sill elevation of about $400 \mathrm{~m}$ below the sea level [14].

\section{Methodology}

The following points describe the methodology followed by the researchers:

1) Satellite imageries are collected based on the criteria shown in the next section;

2) All the imageries are pre-processed and normalized by converting Digital Number (DN) to spectral radiance. 
Then, atmospheric effects are removed. After that, the resulted image is converted to reflectance. Finally, the black gaps are removed if exist;

3) Supervised classification is implemented;

4) Change detection techniques are conducted to study the changes in the area, shape, water level, and volume of the Dead Sea;

5) Results and discussion.

\subsection{Imagery Selection}

In this research, ASTGTM-DEM for 2011 and the Landsat imageries are downloaded from USGS website. The first criterion in data collection is to download even-year imageries including the oldest and newest Landsat archived imageries, 1972 and 2013. The second criterion is to give TM imagery a priority over ETM+ and/or MSS since TM sensor life span is longer than ETM+ (approx. 20 years) so consistent data will be collected. In contrast, Landsat ETM+ imageries have the problem of the Scan Line Corrector Failure (SLC-off) which presents in black gaps. Moreover, Landsat ETM+ has the only advantage of the panchromatic band existence. However, the resolution in the multispectral bands in ETM+ is the same of TM, $30 \mathrm{~m}$. The third criterion is reducing the preprocessing by downloading all imageries in the same date; the month of October is chosen to avoid clouds in the scene. In the case of the October imagery did not match the listed criteria, the closest imagery to October matching the criteria is downloaded. The fourth criterion is downloading full-bands imagery in a Geostationary Earth Orbit Tagged Image File Format (Geo TIFF). The fifth criterion is downloading free clouds scenes, at least above the water-body. Based on these criteria, fifteen imageries were downloaded as illustrated in Table 1 . The only exception was 1975 imagery which is an odd-year imagery. It was preferred to use it because of the lack of satellite imageries from 1973 to 1983.

\subsection{Image Pre-Processing and Normalization}

Since digital sensors record the intensity of electromagnetic radiation from each spot viewed on the Earth's surface as a Digital Number (DN) for each spectral band, the exact range of DN that a sensor utilizes depends on its radiometric resolution. For example, a sensor such as Landsat MSS measures radiation on a 0 - 63 DN scale even as Landsat TM and ETM+ measure it on a 0 - 255 scale [15]. Therefore, normalizing image pixel values for differences in sun illumination geometry, atmospheric effects and instrument calibration is necessary specially because a time series of Landsat imageries will be used, from 1972 to 2013, and compared to each other. The radiometric correction is used to restore the image by using sensor calibration concerned with ensuring uniformity of output across the face of the image, and across time.

Using the Cosine of the Solar Zenith Angle (COST) method, the DN is transformed to reflectance as discussed above. Atmospheric correction using Dark Object Subtraction (DOS) is also included in this method [16][19].

\subsection{Supervised Classification}

In this research, supervised classification was used since the Areas of Interest (AOI) are known and clear to be

\begin{tabular}{cccc} 
Table 1. Imagery data set used in this research. & & \\
\hline Year & Imagery Type & Year & Imagery Type \\
\hline Sep 15, 1972 & MSS & Oct 04, 2000 & TM \\
Jun 29, 1975 & MSS & Oct 18, 2002 & TM \\
Sep 06, 1984 & TM & Jun 17, 2004 & ETM+ \\
Sep 28, 1986 & TM & Oct 13, 2006 + & ETM+ \\
Dec 30, 1988 & TM & Oct 18, 2008 & OLI \\
Aug 30, 1990 & TM & Dec 03, 2010 & Jun 03, 2013 \\
Aug 3, 1992 & TM & & \\
Oct 15, 1998 & TM & & \\
\hline
\end{tabular}


distinguished (the water-body). The spectral signatures of the sea body and the land around are developed and then the software assigned each pixel in the image to the type to which its signature is most similar. The steps performed for supervised classification area are as follows:

- Identifying Training sites;

- Creating spectral signatures for each of the cover types;

- Classifying the entire image pixel by pixel, according to identified signatures.

In term of evaluation how similar signatures are to each other, there are several different statistical techniques that can be used; minimum distance, maximum likelihood classifier and parallelepiped classifier. In this research the maximum likelihood method is used since Reference [20] recommends that if the training sites are well defined — as in the Dead Sea Area — the Maximum Likelihood classifier should produce the best results.

Figure 1 represents the image pre-processing and normalization while Figure 2 represents the image supervised classification process. Finally, removing black gaps in Landsat 7 ETM+ imageries (SLC-off data-contains black gaps, $\mathrm{DN}=0$ ). This type of gaps has been minimized by taking two ETM+ scenes, radio metrically corrected, and then combines them for more complete coverage [21].

\subsection{Change Detection Analysis}

In this stage, area, shape, water level and volume change detection analysis are done using ArcGIS tools. Reference [22] [23] describes a volume estimating method of a watershed by considering it as a bowl. Its volume can be found by delineating a plane across its rim and its curved inner surface. A capping surface can be constructed by connecting a set of points located along the divide, while the inner surface is the modern topography represented by the ASTGTM-DEM. The volume is simply the difference between the cap elevation and topography.

\section{Results and Analysis}

\subsection{The Change in Area over Time}

Historical studies tell that the Dead Sea was separated into two basins in 1978, unfortunately, the earliest im-

DN values with black gaps, Reflectance values with black gaps, Reflectance values without black gaps,

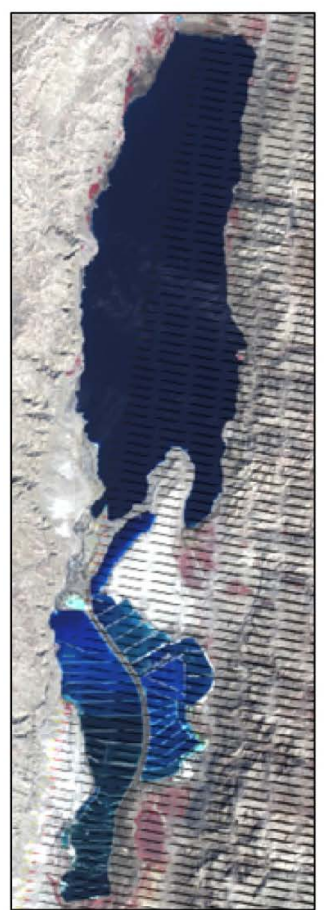

(a)

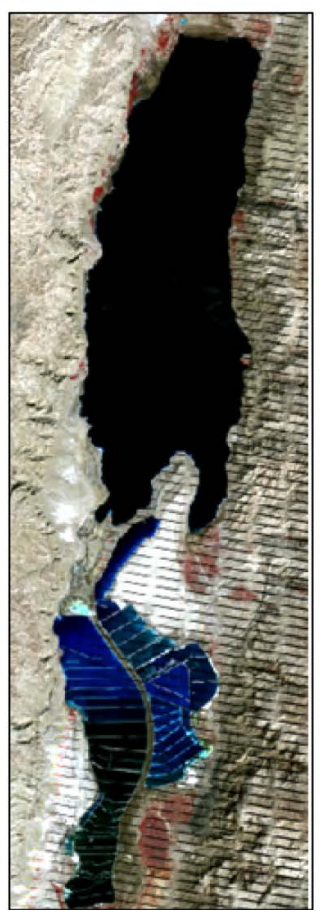

(b)

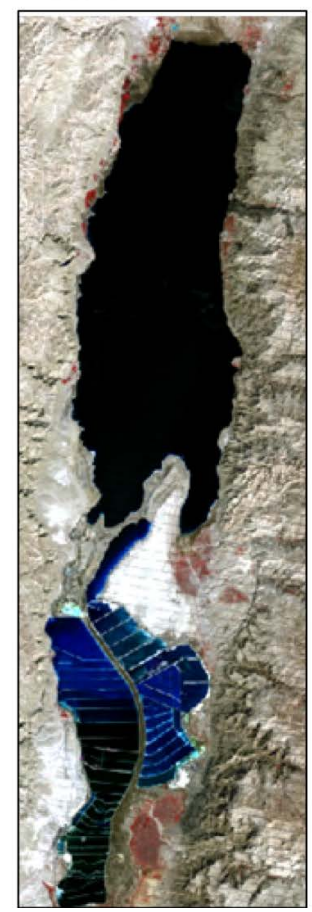

(c)

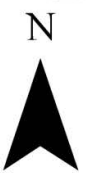

Legend A

DN values with black gaps, (a SLC-off data) which will be converted to spectral radiance.

Legend B

Atmospheric corrected reflectance values with black gaps, Convered from spectral radiance

Legend $\mathrm{C}$

Reflectance values without black gaps, after merging it using the built model with conditional statement

\section{$\begin{array}{lllll}0 & 3 & 6 & 12 & 18\end{array}$}

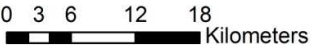
Kilometers

Figure 1. Image pre-processing. 
Areas of Interest (AOI), Supervised classification results,Vectorized water-body for year 2008

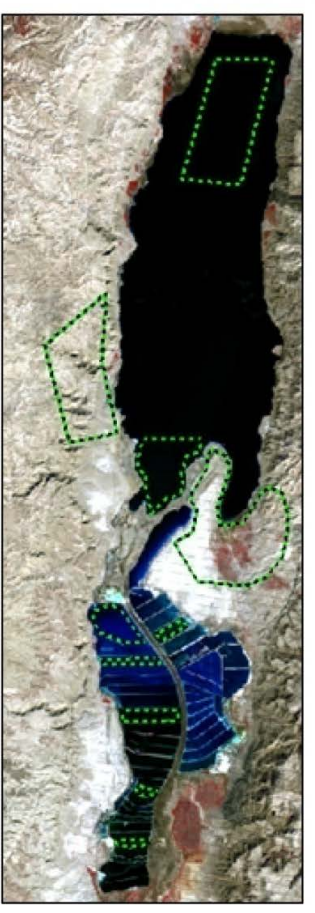

(a)

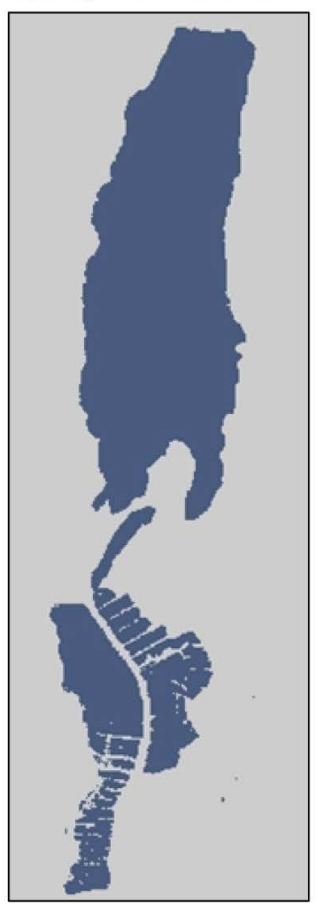

(b)

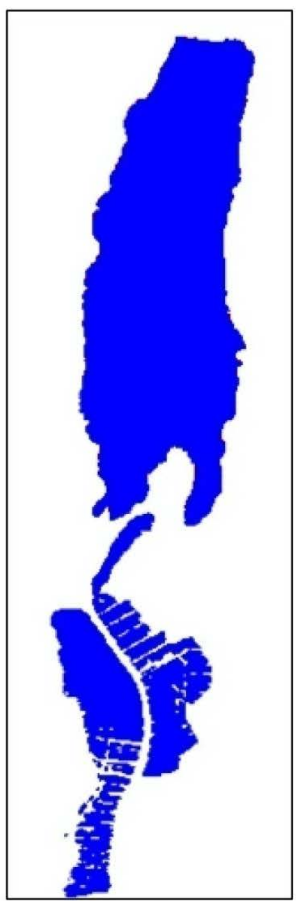

(c)

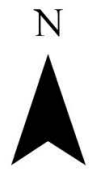

Legend A

Areas of Interest (AOI), which define the water and the land classes

Legend B

Supervised classification results, which describe

the water class (dark gray)

and land class (light gray)

Legend C

The water-body as a vector data type for year 2008

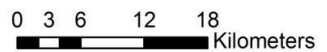

Figure 2. Supervised classification and victorization.

agery which is convenient to the data collection criteria is in 1984, so from this date, it was preferred to distinguish between the two parts with focusing on the northern part since southern part was turned to manmade basins. The general trend of the area of the northern part is decreasing as shown in Table 2. It illustrates that from 1984 to 2013 the area of the northern part decreases in a percentage of $12.4 \%$.

The behavior of this trend is nonlinear and it is noticeable that in 2000, 2004 and 2010 the level increases a little bit if compared with previous and later years. This increasing has been making such a cycle, however this cycle can’t be identified accurately due to the lack of imageries from 1992 to 1998 . Worthy to say, that the decrease between 1984 and 1992 (8 years) reaches 7.98\% while this percentage decreases to 5\% from 1992 to 2013 (21 years). This variation is due the amount used in the industry and the amount of inflow released from Jordan River. Perhaps this variation is also due to the period of time consumed to use the water from the southern part in industrial use. In other words, from 1978 to 1984 is the period needed to use the southern part water and to start compensating by northern part water. In terms of defining the minimum values, it's clear that the area reached the deck in 2013, $611.23 \mathrm{~km}^{2}$. In general, the annual average area change is $-2.98 \mathrm{~km}^{2}$.

Figure 3 represents the change in shape of the water-body from 1972 to 1984 . The change is detected in the eastern part of the south portion of the Dead Sea (before separation) and the bathymetry in the southern portion of the sea began to appear more clearly due to that shrinkage in the area. As discussed so far, this research focuses on the northern part of the Dead Sea since the southern part is converted to manmade evaporation basins. The shape change of the northern part water-body over 14 years, from 1984 to 1998, in general, is detected in two major directions; from the northern west and from the south. The change in area reached $3.7 \%$ in the first year. It is worthy to say that there is no remarkable change in the eastern side of the Dead Sea; this is because the depth of the water is so deep where the fault exists. Over the period from 2000 to 2008, the shrinkage happened in the same direction even though the magnitude of the shrinkages is just $3.7 \%$ which the same percent of shrinkage between 1984 and 1986. However, the area increases in 2010 by about 2\% and decreases again in 2013.

Figure 4 gives the big picture of what happened from 1972 till 2013. It is worthy to say that the behavior of the water-body over time travels from north, northwest and south with no horizontal movement from the east which is very convenient to bathymetric nature. In fact, determining the exact reasons of this shrinkage in this 
Table 2. Areas of the northern \& southern parts of Dead Sea.

\begin{tabular}{cccc}
\hline Year & Area $\left(\mathrm{km}^{2}\right)$ & Northern part $\left(\mathrm{km}^{2}\right)$ & Southern part $\left(\mathrm{km}^{2}\right)$ \\
1972 & 986.21 & \multicolumn{2}{c}{986.21} \\
1975 & 926.01 & 926.01 & \\
1984 & 968.37 & 697.94 & 270.43 \\
1986 & 911.65 & 672.08 & 239.57 \\
1988 & 898.30 & 667.70 & 230.60 \\
1990 & 892.10 & 661.50 & 230.60 \\
1992 & 904.62 & 642.87 & 261.75 \\
1998 & 887.99 & 639.35 & 248.63 \\
2000 & 901.82 & 642.04 & 259.78 \\
2002 & 859.80 & 639.57 & 220.23 \\
2004 & 865.80 & 637.43 & 228.37 \\
2006 & 837.99 & 624.69 & 213.30 \\
2008 & 832.89 & 618.34 & 214.55 \\
2010 & 844.47 & 631.27 & 213.21 \\
2013 & 812.18 & 611.32 & 200.86 \\
\hline
\end{tabular}

The Dead Sea in years 1972,1975 and 1984
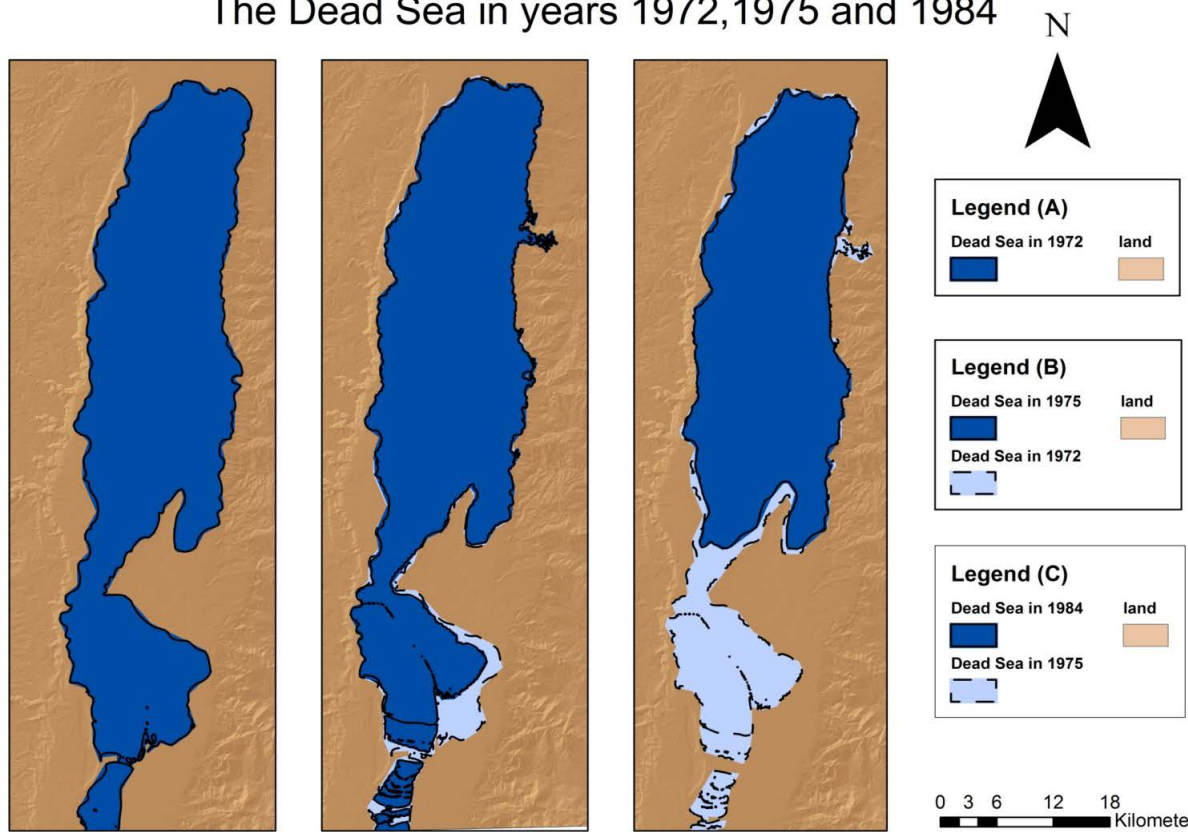

Figure 3. The Dead Sea in 1972, 1975 and 1984.

percentage is too hard and need lots of researches and a closed sea such as the Dead Sea reflects more than one factor. The use of Dead Sea water for the industry by both Israel and Jordan is one of the essential factors that affect the area of the Dead Sea. Moreover, these quantities are roughly estimated even in governmental reports. Climatic conditions play an important part of this behavior of the water body since this behavior is a result of the balance between water running into the sea from the tributary area and direct precipitation, minus water evaporation. In any case, the main reason causing this dramatic recession in the Dead Sea area is the intensive human water consumption from the Jordan and Yarmouk Rivers for other usages. Israel transfers huge quantities of 

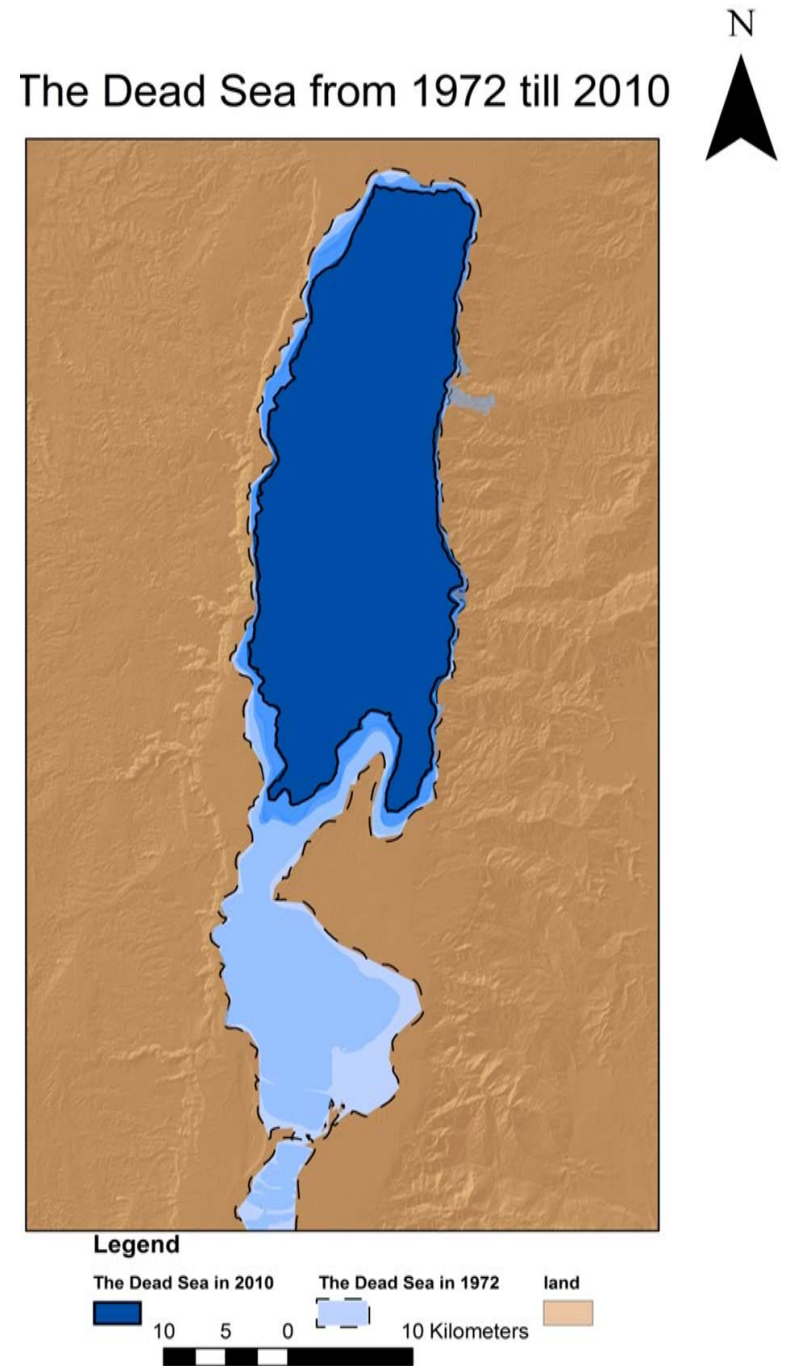

Figure 4. The Dead Sea from 1972 till 2013.

surface water through the National Water Carrier from Upper Jordan River to the Negev, where these quantities equal $420 \mathrm{MCM} /$ year in addition to local consumption in the Tiberius Basin and the Huleh Valley. By studying the trend behavior of this decrease, a third degree polynomial could be derived from regression analysis as shown in Figure 5 with $\mathrm{R}^{2}=0.943$ which indicates that the derived equation is representative.

\subsection{The Change in Water Level over Time}

The derivation of the Dead Sea level is not a straight forward process even though the results are consistent with area changing as well as with previous studies, as will be discussed later. Table 3 illustrates the average Dead Sea level derived using the satellite imageries in collaboration with ASTGTM-DEM raster data. The table shows the standard deviation representing the variance values of these derived points about the average. It is obvious that from 1984 to 2013 the water level of northern part decreased by about $25.83 \mathrm{~m}$ and this decrease reached more than this in 2006 and 2008. Since the behavior of this trend is nonlinear, it is noticeable that from 1975 to 1984 the Dead Sea level raised dramatically by $6.6 \mathrm{~m}$, perhaps this is due to the separation as discussed in the area change detection section. However, there is no point in finding a relation between water level and area before and after the separation since the boundary conditions is totally changed. The change in water level between 1984 and 1986 could be justified by the changing in water-body area. In 2006 and 2008, the water levels reached the deck which corresponds to the change in the area in these years. In general, every year the average water 


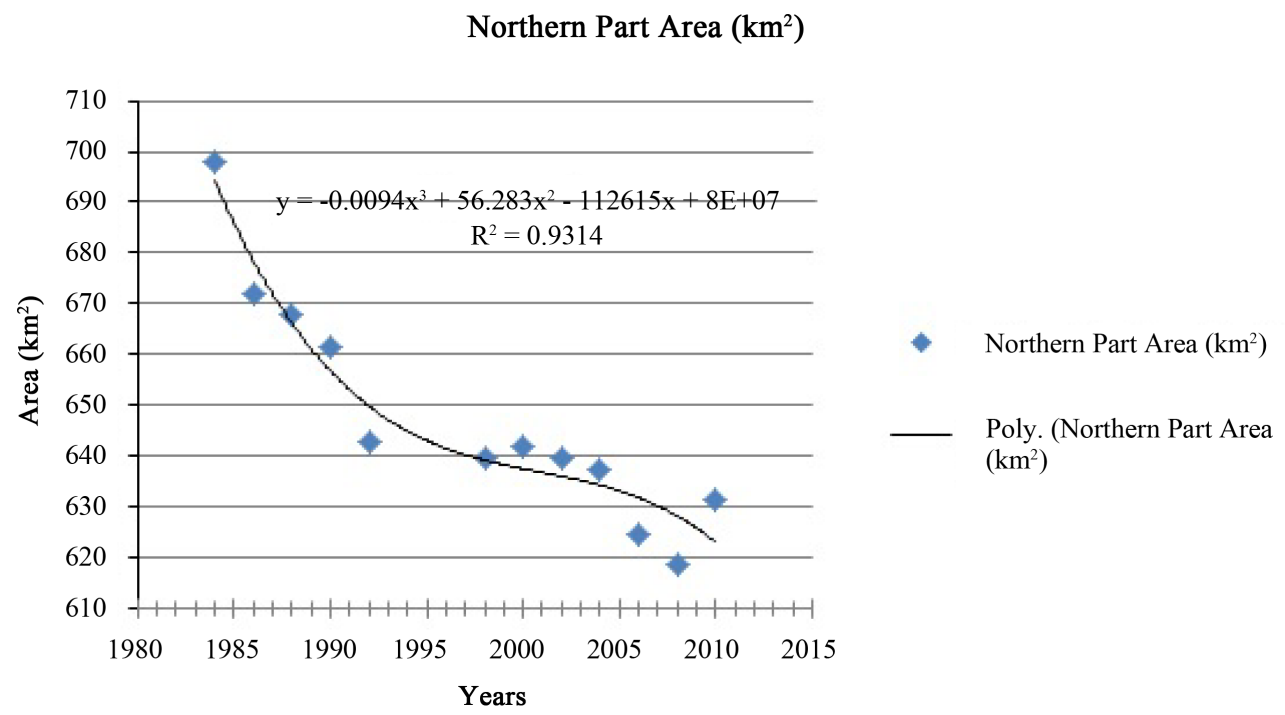

Figure 5. Regression analysis of the northern Dead Sea.

Table 3. The average Dead Sea level in meters.

\begin{tabular}{ccc}
\hline Year & Area $\left(\mathrm{km}^{2}\right)$ & Standard Deviation \\
1972 & -404.30 & 7.2 \\
1975 & -404.80 & 6 \\
1984 & -411.40 & 8 \\
1986 & -420.00 & 8 \\
1988 & -419.5 & 7.5 \\
1990 & -421.32 & 7.1 \\
1992 & -424.30 & 14 \\
1998 & -427.90 & 6 \\
2000 & -427.30 & 5 \\
2002 & -428.20 & 5.1 \\
2004 & -428.90 & 4.7 \\
2006 & -431.10 & 2.5 \\
2008 & -431.00 & 2.6 \\
2010 & -429.90 & 4.5 \\
2013 & -430.13 & 5.36 \\
\hline
\end{tabular}

level change is $-0.65 \mathrm{~m}$. Reference [12] gets a close result in his research $-0.7 \mathrm{~m} /$ year. By studying the trend behavior of this decrease, a third degree polynomial could be derived from regression analysis as shown in Figure 6 with $\mathrm{R}^{2}=0.9506$ which indicates that the derived equation is representative.

\subsection{Area-Water Level Relationship}

In order to find the relation between the Dead Sea area and its water level, regression analysis is used putting the areas on $\mathrm{x}$-axis and corresponding water level on $\mathrm{y}$-axis to get a linear equation with $\mathrm{R}^{2}=0.9672$ which is considered a strong relation between both, see Figure 7. Therefore from this relation, the water level could be estimated without even ASTGTM-DEM, just by using satellite imageries. 
Water level m (MSL)

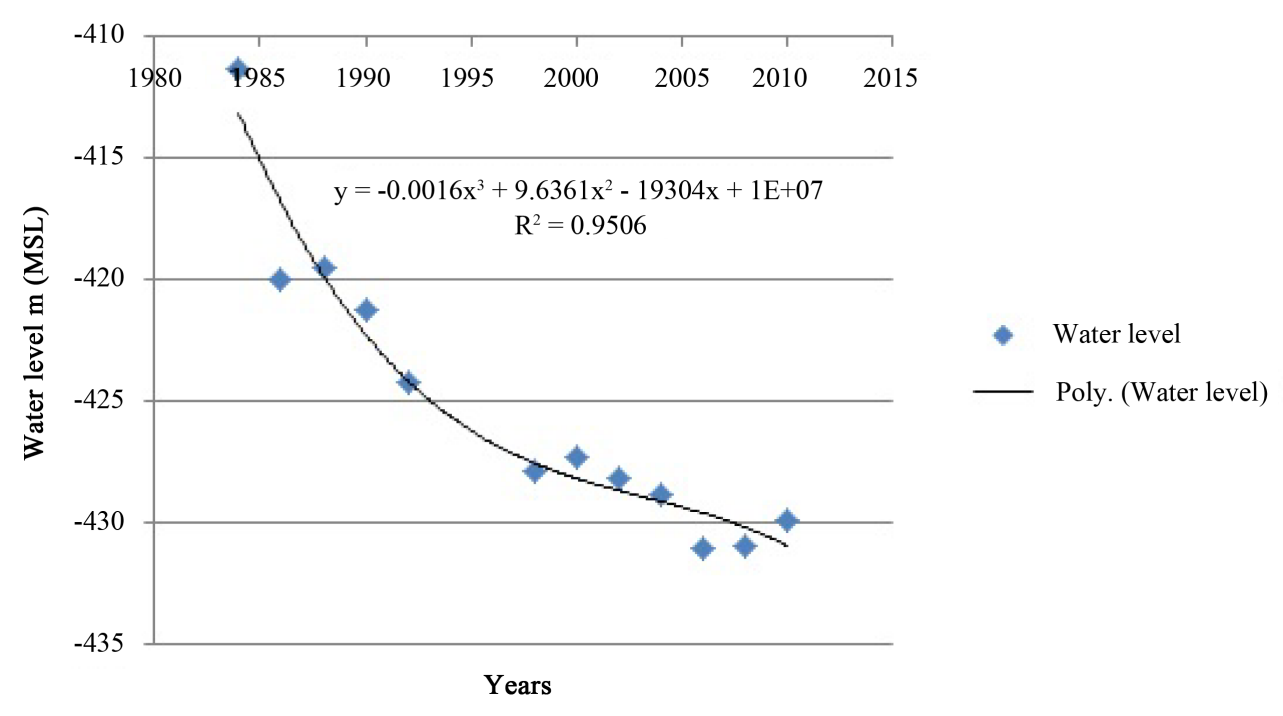

Figure 6. Water level through time.

Area-Water level relation

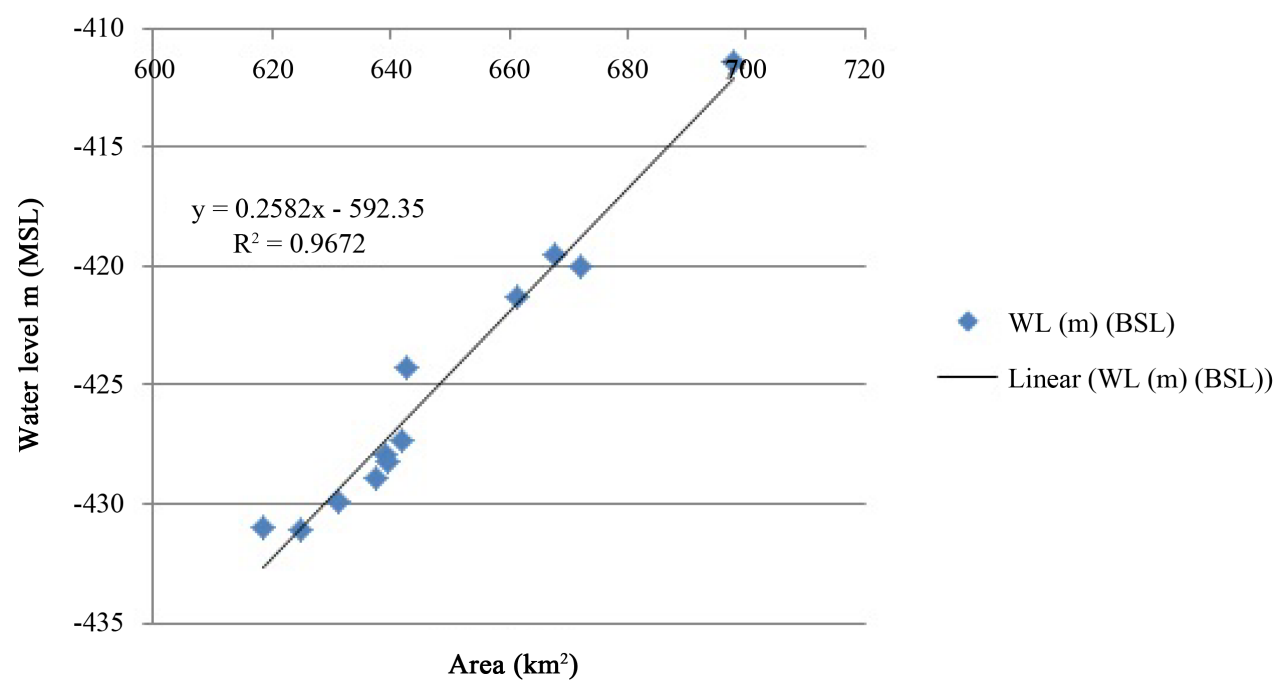

Figure 7. Area water level relation.

\subsection{The Change in Volume over Time}

Based on the area and water level derivations, the volume change could be calculated. Figure 8 illustrates the volume changing from the referential year, 1984. In general, every year the average volume change is $-0.42 \mathrm{~km}^{3}$.

\section{Conclusion}

The area of the Dead Sea surface (at the end of the fifties) is about $1000 \mathrm{~km}^{2}$. The altitude of the surface is around $350 \mathrm{~m}$ below sea level. Since 1978, the Dead Sea has retreated, and the sea body turned into two basins: the principal northern one that was about $631.27 \mathrm{~km}^{2}$ with a water level of $-430.13 \mathrm{~m}$ (in 2013), and the shallow southern one with the Lisan Peninsula and the Lynch Straits in between, which has a sill elevation of about 400 $\mathrm{m}$ below the sea level. The Dead Sea shrinks by $2.9 \mathrm{~km}^{2} /$ year while the water level decreases by $0.65 \mathrm{~m} /$ year. Consequently, the volume changes by $-0.42 \mathrm{~km}^{3} /$ year. The direction of this shrinkage is from the north, north- 


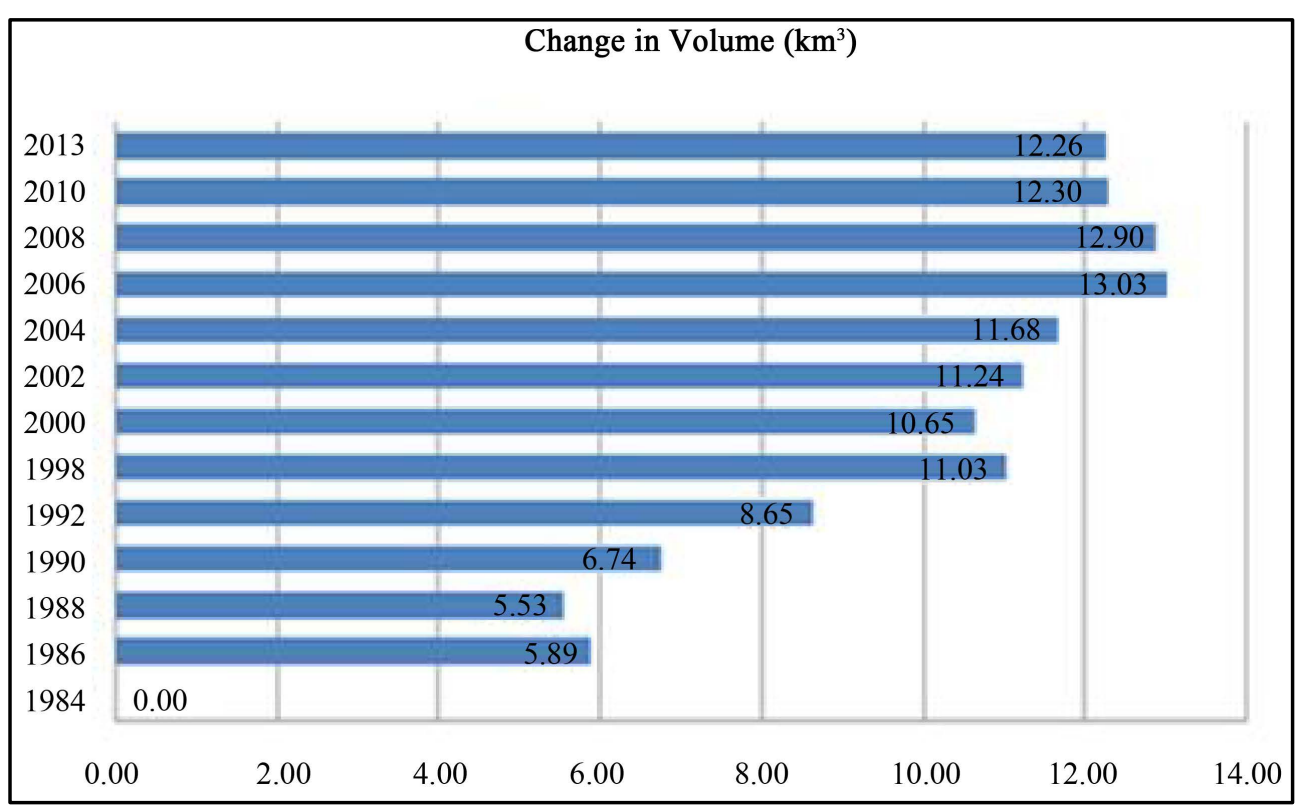

Figure 8. Volume change over time.

west and from the south direction of the northern part due to slopes of bathymetry. No shrinkage was considered from the east direction due to the same reason since the bathymetric slope is so sharp.

\section{References}

[1] Smith, R.B. (2012) Introduction to Remote Sensing. Lecture Notes.

[2] Gong, J.Y., et al. (2008) A Review of Multi-Temporal Remote Sensing Data Change Detection Algorithms. The International Archives of the Photogrammetry, Remote Sensing and Spatial Information Sciences (Hong Kong), 37, 757-762.

[3] Singh, A. (1989) Digital Change Detection Techniques Using Remotely-Sensed Data. International Journal of Remote Sensing, 10, 989-1003.

[4] Kandare, K. (2000) The Time Series Change Detection Methods of Remote Sensing. ISPRS SC Newsletter, Vienna.

[5] AUG Signals (2012) Change Detection. AUG SIGNALS. (Online) http://www.augsignals.com/page.php?menu=14

[6] Deer, P. (1999) Digital Change Detection Techniques. Civilian and Military Application Published in the UK. Taylar \& Francis Ltd., London.

[7] Lu, D., et al. (2004) Change Detection Techniques. Taylor \& Francis Ltd., London.

[8] Richard, J., et al. (2005) Image Change Detection Algorithms. A Systematic Survey. IEEE Transactions on Image Processing, 14, 294-307.

[9] Théau, J. (2012) Change Detection. In: Danko, D.M. and Kresse, W., Eds., Springer Handbook of Geographic Information, Springer, New York, 7.

[10] Omar, M. (1996) Shrinking of Dead Sea Raises Deep Environmental Concerns. Christian Information Centre, Jerusalem.

[11] Al-Zubaidy, R., Khaled, M. and Shambour, Y. (2011) Prediction of the Dead Sea Water Level Using Neural Networks. 4th International Symposium on Innovation in Information \& Communication Technology, Amman, 29 November-1 December 2011, 147-154.

[12] Abu Ghazleh, S., et al. (2010) Rapidly Shrinking Dead Sea Urgently Needs Infusion of 0.9 km 3/a from Planned RedSea Channel: Implication for Renewable Energy and Sustainable Development. 4, 1995-6665.

[13] Morin, E., et al. (2009) Flash Flood Prediction in the Dead Sea Region Utilizing Radar Rainfall Data. Journal of DeadSea and Arava Research, 1, 1066-1076.

[14] US Geological Survey (1998) Overview of Middle East Water Resources: Water Resources of Palestinian, Jordanian and Israeli Interest. Water Data Bank Project, Executive Action Team, New York, 41. 
[15] Green, E.P., et al. (2000) Remote Sensing Handbook for Tropical Coastal Management. UNESCO, Paris.

[16] Chavez, Jr. (1996) Image-Based Atmospheric Corrections-Revisited and Improved. Photogrammetric Engineering and Remote Sensing, 62, 1025-1036.

[17] Wen, W. (2008) Wetland Change Prediction Using Markov Cellular Automata Model in Lore Lindu National Park Central Sulawesi Province. Master Thesis, BOGOR Agricultural University, Indonesia.

[18] Ramsey, R.D. (2013) Image Standardization. RS/GIS Laboratory. (Online) http://earth.gis.usu.edu/imagestd/

[19] Irons, J. (2013) Chapter 11. Landsat Hand Book. NASA. (Online) http://landsathandbook.gsfc.nasa.gov/data_prod/prog_sect11_3.html

[20] Chinea. J.D. (2013) Supervised Classification. Universidad de Puerto Rico, Recinto Universitario de Mayagüez. (Online) http://www.uprm.edu/biology/profs/chinea/gis/lectesc/tut4_3.pdf

[21] USGS (2008) Landsat Update. Landsat Update.

[22] Akin, E. and Cooley, S. (2013) Lake Basin Volume. GIS 4 Geomorphology. (Online) http://gis4geomorphology.com/lake-basin-volume/\#more-1239

[23] Cooley, S. (2013) Minimum Eroded Volume. GIS 4 Geomorphology. (Online) http://gis4geomorphology.com/calculate-basin-volume/\#more-8 
Scientific Research Publishing (SCIRP) is one of the largest Open Access journal publishers. It is currently publishing more than 200 open access, online, peer-reviewed journals covering a wide range of academic disciplines. SCIRP serves the worldwide academic communities and contributes to the progress and application of science with its publication.

Other selected journals from SCIRP are listed as below. Submit your manuscript to us via either submit@scirp.org or Online Submission Portal.
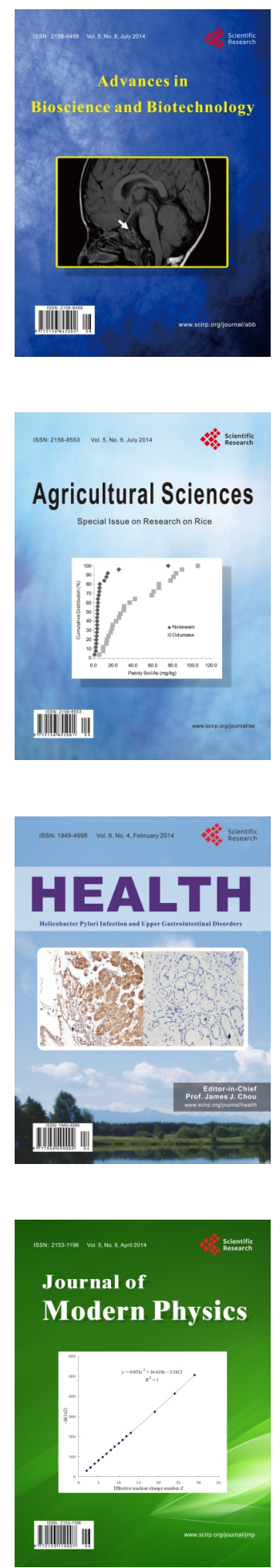
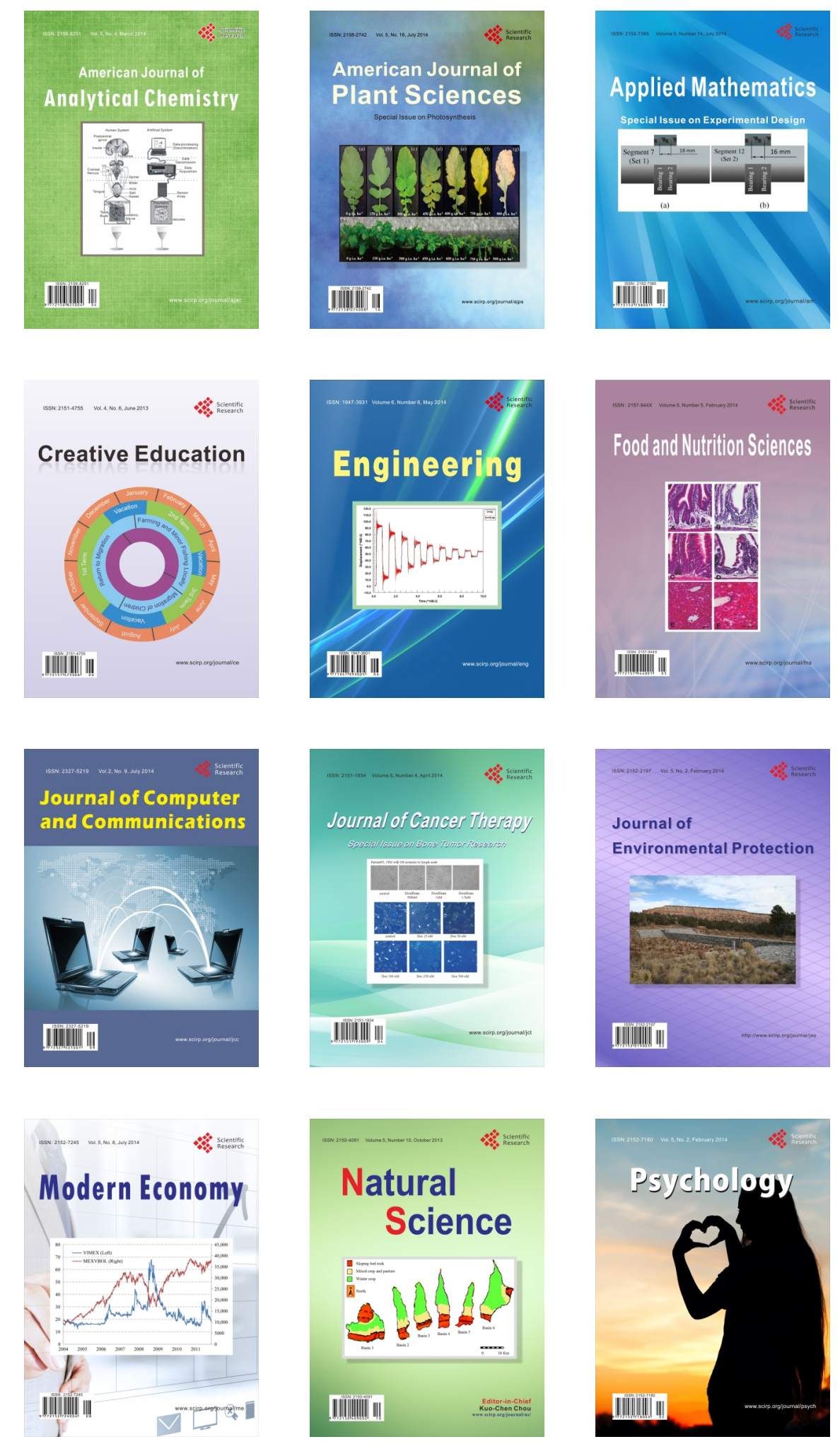